\title{
AVALIAÇÃO NO ENSINO FUNDAMENTAL: REFLEXÕES SOBRE O REGIME DE PROGRESSÃO CONTINUADA
}

\author{
EVALUATION IN ELEMENTARY EDUCATION: \\ REFLECTIONS ON THE PROGRESSION \\ REGIMEN CONTINUED
}

\section{EVALUACIÓN EN EDUCACIÓN BÁSICA: REFLEXIONES SOBRE EL RÉGIMEN DE PROGRESIÓN CONTINUADO}

\author{
Karen Fabiane Leonel CorrêA ${ }^{\mathrm{I}}$ \\ EVANDRo ANTONIO CORRÊA ${ }^{I I}$
}

\begin{abstract}
Resumo Estudo de caráter teórico-reflexivo, tem como objetivo compreender as características do regime de Progressão Continuada para o Ensino Fundamental no Estado de São Paulo, de acordo com estudos realizados acerca da temática e conforme a Deliberação Conselho Estadual de Educação (CEE) nº. 9/97. Nesse sentido, os desdobramentos deste estudo têm um olhar voltado para a política de progressão continuada do Estado de São Paulo, as justificativas para a sua criação, os resultados e os possíveis avanços, ou não, proporcionados após sua implementação. Esse regime de avaliação foi objeto de discussão desde a década de 1950 no Brasil, sendo consolidado no Estado de São Paulo a partir da década de 1990. Após vários debates, o regime foi implantado na rede pública estadual a partir de 1998. Sob esta ótica, conclui-se que estudos apontam avanços e outros pontuam que o sistema seria o culpado pelas dificuldades em sala de aula, relacionadas à aprovação, desinteresse e indisciplina dos alunos.
\end{abstract}

Palavras-chave: Progressão Continuada; Avaliação; Estado de São Paulo.

Abstract Theoretical and reflective character study, it aims to understand the characteristics of the Continued Progression Scheme for Elementary Education in the State of São Paulo, according to studies about the theme and as Deliberation State Education Council (EEC) $n^{\circ} .9 / 97$. In this sense, the unfolding of this study has an eye toward continued pro-

\footnotetext{
I Secretaria de Educação do Estado de São Paulo - E.E. "Frei Galvão", São Paulo/SP - Brasil

II Faculdades Integradas de Jaú Faculdade Gran Tietê - Barra Bonita/SP - Brasil
} 
gression policy of the State of São Paulo, the reasons for its creation, the results and the possible advances or not provided after its implementation. This evaluation process was the subject of discussion since the 1950s in Brazil, consolidated in the state of Sao Paulo from the decade of 1990. After several discussions, the system was implemented in public schools since 1998. Under this optical, it concludes that studies show advances and other punctuate the system would be to blame for the difficulties in the classroom, related to the approval, indifference and indiscipline of students.

Key-words: Continuous Progression; Evaluation; State of São Paulo.

Resumen Estudio de carácter teórico y reflexivo, su objetivo es comprender las características del esquema de progresión continua para la Educación Primaria en el Estado de São Paulo, según estudios sobre el tema y como Consejo de Deliberación Estado de Educación (CEE) $n^{\circ}$. 9/97. En este sentido, el desarrollo de este estudio tiene la mirada puesta en la política de continua progresión del Estado de São Paulo, las razones de su creación, los resultados y los posibles avances o no previsto después de su aplicación. Este proceso de evaluación fue objeto de debate desde los años 1950 en Brasil, consolidada en el estado de Sao Paulo desde la década de 1990. Después de varias discusiones, el sistema fue implementado en las escuelas públicas desde 1998. Bajo esta óptico, se concluye que los estudios muestran avances y otra marcan el sistema sería el culpable de las dificultades en el aula, en relación con la aprobación, la indiferencia y la indisciplina de los alumnos.

Palabras claves: Progresión Continua; Evaluación; Estado de São Paulo.

\section{INTRODUÇÃo}

Nos últimos anos, um dos temas que têm gerado debate constante refere-se à política de Progressão Continuada, principalmente, implementada nas Políticas Públicas do Estado de São Paulo no âmbito da Educação. Por sua vez, o Estado de São Paulo adotou o regime da progressão continuada para o Ensino Fundamental, conforme a Deliberação Conselho Estadual de Educação (CEE) nº. 9/97 e homologada pela Resolução Secretaria de Educação (SE) de 4/8/97, que vem sendo objeto de discussão no meio acadêmico, nas escolas, entre professores, alunos e comunidade.

Com base na Lei $n^{\circ}$. 9.394/96, a qual estabelece as diretrizes e bases da Educação Nacional (LDB), no parágrafo $2^{\circ}$. prevê que os "estabelecimentos que utilizam progressão regular por série podem adotar no ensino fundamental o regime de progressão continuada, sem prejuízo da avaliação do processo de ensino-aprendizagem, observadas as normas do respectivo sistema de ensino" (BRASIL, 1996). E uma das possibilidades da implementação do regime de progressão continuada, de acordo com Correa e Piotto (2009, p. 2), seria em "resposta às críticas a um sistema de ensino inextrincavelmente ligado à produção do fracasso escolar e a seus alarmantes índices, a partir de meados da década de 1990 começam a surgir políticas educacionais de combate ao fracasso escolar".

A partir de então, com a prática docente percebemos algumas mudanças consideráveis, tanto no comportamento em sala de aula quanto no tratamento dado às atividades realizadas no percurso de formação. Como exemplo, em nossa docência, observamos que 
alguns alunos do nono ano ${ }^{1}$ mal conseguiam ler parágrafos curtos, bem como, tinham dificuldade para compreender questões explícitas em um texto voltado para o quinto ano, e que não se importavam em melhorar, dizendo sempre "eu vou passar de qualquer jeito", ou seja, uma possível distorção da proposta por parte dos alunos e até mesmo de professores, equipe gestora e poder público.

Mediante esse discurso, recorrente no contexto educacional, cabe reflexão sobre o regime da progressão continuada, a fim de colaborar com o debate referente às possíveis mudanças metodológicas no processo de rendimento escolar e desempenho do aluno e as possibilidades de avanço "nas séries mediante verificação do aprendizado" (BRASIL, 1996) por meio da avaliação.

Cavalcanti Neto e Aquino (2009, p. 228), nesse sentido, ponderam que a avaliação deveria ser entendida como "um meio imprescindível para a aprendizagem, o processo educativo deve apontar para a construção de uma prática avaliativa qualitativamente mais significativa, comprometida com a aprendizagem e, consequentemente, com o crescimento pessoal e intelectual do educando".

Dada à amplitude do assunto, como recorte de estudo buscou-se compreender quais as características do regime de progressão continuada para o Ensino Fundamental de acordo com estudos realizados referentes à temática? No que diz respeito aos objetivos, procuramos identificar as implicações da política de progressão continuada do Estado de São Paulo, a fim de conhecer as justificativas para a sua criação, resultados e, após sua implementação, os possíveis benefícios e avanços, ou não.

Nesse itinerário, Lüdke e André (1986, p. 1) alertam que "para se realizar uma pesquisa é preciso promover o confronto entre os dados, as evidências, as informações coletadas sobre determinado assunto e o conhecimento teórico acumulado a respeito dele". No âmbito desse processo, tendo no paradigma do construtivismo social o seu ponto de partida, pois se entende que é necessário compreender o histórico social das determinações legais. O construtivismo social "é uma abordagem de pesquisa que tem suas raízes na fenomenologia, considerando os aspectos subjetivos do comportamento humano e preconizando a entrada no universo conceitual dos sujeitos (o sentido que os sujeitos dão aos acontecimentos e as interações sociais de sua vida diária)" (ANDRÉ, 1995, p. 16-18).

Tendo em vista o objeto do trabalho, recorreu-se a fontes bibliográficas, ou seja, informação em livros e periódicos referentes aos temas envolvidos no estudo, como Freitas (2002), Viégas (2002), Mainardes (2006), Neves e Boruchovitch (2001), Bertagna (2010), Souza (1998), entre outros. Além de recorrer à pesquisa documental, em fontes primárias de investigação (documentos oficiais), com especial atenção a LDB (BRASIL, 1996), CEE $n^{\circ}$. 09/97, Indicação CEE Nº. 22/97, Unificação de Dispositivos Legais e Normativos relativos ao Ensino Fundamental e Médio, e documentos e notícias da Associação dos Professores do Estado de São Paulo (Apeoesp).

Artigo 32. O ensino fundamental obrigatório, com duração de nove anos, gratuito na escola pública, iniciando-se aos seis anos de idade, terá por objetivo a formação básica do cidadão [...]. [Redação dada pela Lei $\underline{\mathrm{n}^{\circ} .11 .274, \text { de } 2006}$ (BRASIL, 2006)]. 


\section{Progressão continuada: um olhar sobre a legislação}

Cabe lembrar que ao conversarmos com colegas de profissão (professores da Educação Básica - Ensino Fundamental II), havia algumas reclamações como: após a progressão continuada os estudantes perderam a motivação; e o que realmente importava para os órgãos oficiais era a diminuição do número de alunos reprovados, independentemente, do aprendizado e/ou a qualidade de ensino. Certos ou equivocados, devemos compreender que o regime exige "um novo tratamento para o processo de avaliação na escola, transformando-o num instrumento-guia essencial para a observação da progressão do aluno" (SÃO PAULO, 1997, p. 947).

Para Correa e Piotto (2009, p. 2), a implementação de tais programas:

[...] não resultou em um maior número de crianças e adolescentes beneficiando-se do que a escola oferece ou deveria oferecer, como evidenciam reincidentemente as avaliações externas de rendimento escolar, que mostram, ano após ano, por exemplo, crianças analfabetas em séries bastante adiantadas do ensino fundamental.

Infelizmente, essas ocorrências de alunos com as dificuldades já apontadas são uma constante no cotidiano da ação como docentes, os quais motivaram a compreender melhor o processo de ensino/aprendizagem e, por conseguinte, a buscar o porquê da Progressão Continuada.

Dessa maneira, acerca das ações concretas e um olhar crítico, Tancredi (sd) coloca que o professor reflexivo está comprometido com a aprendizagem dos estudantes e ligado ao que acontece na escola como um todo e não apenas em suas classes, tentando adequar (ou não) sua atuação às políticas educacionais.

Portanto, a fim de compreender o regime da Progressão Continuada, o qual está previsto na LDB 9.394/96, conforme mencionado, o Estado de São Paulo, apoiado nessa Lei, no Artigo $2^{\circ}$. da Lei Estadual n ${ }^{\circ}$. 10.403, de 6 de julho de 1971, e na Indicação $n^{\circ}$. 08/97, garantido na Deliberação Conselho Estadual de Educação (CEE) no. 9/97 e homologada pela Resolução Secretaria de Educação (SE) de 4/8/97, instituiu o regime a partir do ano de 1998 , tendo como fundamento para a sua implementação assegurar que as crianças tivessem a permanência e sucesso garantidos, por meio do respeito das possibilidades de cada um aprender, o que levaria à construção da cidadania.

O CEE, para a aprovação do regime da Progressão Continuada, colocou como justificativa assegurar a permanência da criança na escola com sucesso, ampliando as possibilidades de aprendizagem dos estudantes, o que faria que se diminuísse a elitização do ensino e a exclusão social dos indivíduos. Na indicação do CEE $n^{\circ}$. 22/97 - CP - aprovada em 17/12/97, o regime de progressão continuada exige um novo tratamento para o processo de avaliação na escola, transformando-o num instrumento-guia essencial para a observação da progressão do aluno (SÃO PAULO, 1997b, p. 947). 
Os conselheiros dessa indicação ponderaram, ainda, que esse regime pedia avaliação continuada do processo de aprendizagem dos alunos, o qual deveria ser objeto de recuperação continuada e paralela, a partir de resultados periódicos parciais e, se necessário, no final de cada período letivo (SÃO PAULO, 1997b, p. 947).

No entanto, para se compreender melhor a temática, recorremos a alguns elementos regidos pelos órgãos oficiais do Estado de São Paulo que atuam na Educação Estadual como: o

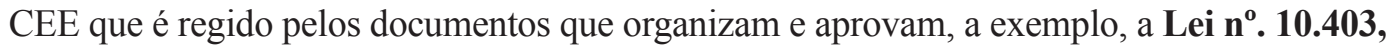
de 6 de julho de 1971, que reorganiza o Conselho Estadual de Educação; Decreto no .52 .811 , de 6 de outubro de 1971, que aprova o Regimento do Conselho Estadual de Educação; o Decreto $n^{\circ} .9 .887$, de 14 de junho de 1977, que organiza as unidades de apoio técnico e administrativo do Conselho Estadual de Educação, definindo as competências das autoridades desse órgão e dá providências correlatas; a Deliberação CEE Nº. 17/73, que aprova o Regimento das Sessões do Conselho Estadual de Educação; a Deliberação CEE Nº. 13/95, que dispõe sobre encaminhamento de recursos ao Conselho Estadual de Educação.

Nesse interim, entende-se que o CEE é um órgão normativo, deliberativo e consultivo da educação pública e privada do Estado de São Paulo. Além dessas atribuições, o órgão estabelece regras para todas as escolas de todas as redes - as estaduais, municipais e particulares de ensino infantil, fundamental, médio e profissional presencial ou a distância. Esse órgão ainda orienta e credencia os cursos das instituições de Ensino Superior do Estado. Apresenta a função de orientar a comunidade - população, escolas, instituições mantenedoras, profissionais da educação - além de sugerir, acompanhar e avaliar políticas, descentralizando decisões, devendo atuar com autonomia e fixar, por meio de Pareceres e de Indicações, os princípios e os parâmetros educacionais a fim de definir objetivos que devem balizar a elaboração do Plano Estadual de Educação.

Todavia, ao se pensar, elaborar e antes de definir qualquer mudança, concordamos com a importância de que "pensar sobre políticas públicas implica conceber a realidade social dialeticamente, como um fenômeno complexo, em constante movimento, sujeito a imprevisibilidades" (FALSARELLA, 2013, p. 257). E ainda, referente às decisões governamentais no que tange às políticas públicas, não deveriam se reduzir à elaboração de um rol de intenções nem se esgotar na tomada de decisões pelo governo, pois necessitam de compromisso com a ação. Para autora, "não com qualquer ação. Há que se selecionar ações estratégicas em função do princípio de garantia de direitos e da previsão de recursos para efetivá-las" (p. 258).

Dessa maneira, o CEE, por meio de seus pronunciamentos e de atos, define sua vocação como órgão técnico e atuante no estabelecimento de políticas públicas, fixando por meio de Pareceres, Indicações e Deliberações - posições que expressam as diretrizes fundamentais de uma política educacional para o Estado de São Paulo, considerando não apenas a realidade educacional presente, assim como as perspectivas de sua melhoria a médio e longo prazo.

Outro órgão consultado foi o Centro de Referência de Educação Mário Covas (CRE), idealizado pela Secretaria de Estado da Educação de São Paulo, que tem como objetivo 
tornar-se um referencial pedagógico de excelência na disseminação da informação educacional. Para atender a esse objetivo, conta com um acervo documental o qual pode ser consultado fisicamente (em sua sede) ou acessado virtualmente.

Mediante o acervo do CRE, foram consultados alguns textos e ações realizadas a respeito da implementação do regime de Progressão Continuada. Uma destas foi o fórum "Progressão Continuada: compromisso com a aprendizagem", em 2002, do qual participaram dirigentes de ensino e dois representantes da Diretoria de Ensino (DE), do CEE, da Undime (União dos Dirigentes Municipais da Educação), das entidades de classe (Apeoesp, Apase, Sindicato de Supervisores de Ensino do Magistério Oficial no Estado de São Paulo), do Centro de Professorado Paulista (CPP), do Sindicato de Especialistas de Educação do Magistério Oficial do Estado de São Paulo (Udemo), da Secretaria Estadual de Educação, das Universidades/Faculdade de Educação: USP, Unesp, Unicamp, PUC, e de Conselho de Escola/Associação de Pais e Mestres (APM).

No acervo do CRE, há uma entrevista com o ex-secretário da Educação do Estado de São Paulo (mandato de 2003 a 2007), Gabriel Chalita, na qual tenta explicar as principais motivações para o regime e também desfazer as principais críticas ao regime de Progressão Continuada. O ex-secretário colocou, no momento, que "o conceito da progressão continuada é o fato de que todo mundo pode aprender. E que o processo de aprendizagem não precisa ser o mesmo para todos os alunos".

Para Souza (1998), quando da implantação do sistema de ciclos, ao prever a progressão continuada, presume tratar o conhecimento como processo e, dessa forma, como uma vivência que não compartilha com a ideia de interrupção, "mas sim de construção, em que o aluno é situado como sujeito da ação, que está continuamente sendo, formado, ou melhor, construindo significados, a partir de relações dos homens com o mundo e entre si” (p. 85).

Sobre o assunto, a Deliberação CEE $n^{\circ} .9 / 97$, Artigo $1^{\circ}$. - Parágrafo $3^{\circ}$., expõe que o regime de progressão continuada garante "a avaliação do processo de ensino-aprendizagem, o qual deve ser objeto de recuperação contínua e paralela, a partir de resultados periódicos parciais e, se necessário, no final de cada período letivo" (SÃO PAULO, 1997a, p. 820).

Essa Deliberação, no Artigo $3^{\circ}$., dentro do projeto educacional, com a implantação do regime, deve especificar mecanismos a fim de assegurar, entre outros:

\footnotetext{
I - avaliação institucional interna e externa;

II - avaliações da aprendizagem ao longo do processo, conduzindo a uma avaliação contínua e cumulativa da aprendizagem do aluno, de modo a permitir a apreciação de seu desempenho em todo o ciclo;

III - atividades de reforço e de recuperação paralelas e contínuas ao longo do processo e, se necessárias, ao final de ciclo ou nível;

IV - meios alternativos de adaptação, de reforço, de reclassificação, de avanço, de reconhecimento, de aproveitamento e de aceleração de estudos;

$\mathrm{V}$ - indicadores de desempenho;

VI - controle da frequência dos alunos;

VII - contínua melhoria do ensino;
} 
VIII - forma de implantação, implementação e avaliação do projeto;

IX - dispositivos regimentais adequados;

$\mathrm{X}$ - articulação com as famílias no acompanhamento do aluno ao longo do processo, fornecendo-lhes informações sistemáticas sobre frequência e aproveitamento escolar (SÃO PAULO, 1997a, p. 821).

Com base nesses indicativos, o relatório do CEE de São Paulo sobre a Indicação n ${ }^{\circ}$. 8/97, que aprovou o regime de progressão continuada, considerou a proposta da Secretaria de Educação como uma estratégia que vai viabilizar a universalização da educação básica, garantir o acesso e a permanência dos alunos em idade própria na escola, bem como, regularizar o fluxo dos alunos no que se refere à relação idade/série e da melhoria geral da qualidade do ensino.

No entanto, "as sugestões contidas no relatório não foram seguidas pela Secretaria de Educação, que optou pela implantação do regime de progressão continuada sem consulta e sem participação, seja dos trabalhadores em educação, ou da comunidade usuária", conforme pontuou Jacomini (2004, p. 414).

A Indicação $n^{\circ}$. 8/97 traz o posicionamento da APASE, de acordo com documento de 28 de julho de 1997, o qual foi encaminhado à CEE, que se manifestou entendendo que "o 'nó' da educação está na avaliação ou na verificação do rendimento escolar. A avaliação contínua e cumulativa é o ideal a atingir e, a nosso ver, não seria producente colocarmos obstáculos que impeçam a consecução desse ideal [...]" (SÃO PAULO, 1997a, p. 824). E de acordo com Indicação $\mathrm{CEE} n^{\circ}$. 22/97, a avaliação no contexto da progressão continuada ganha novo sentido, de forma ampliada e trampolim do progresso do aluno e não mais o de um mero instrumento de seletividade (SÃO PAULO, 1997b, p. 948).

Dessa forma, é necessário ir além, segundo Bertagna (2008, p. 82), da compreensão dos ciclos de formação, "superando-se a concepção de 'solução pedagógica' em contraposição à seriação, para se constituir em 'instrumentos para o desenvolvimento de novas relações' escolares e sociais contrapostas às vividas/impostas pela atual sociedade". Todavia, caberia entender o regime de progressão continuada "como um mecanismo inteligente e eficaz de ajustar a realidade do fato pedagógico à realidade dos alunos, e não um meio artificial e automático de se 'empurrar' os alunos para as séries, etapas, fases subsequentes" (SÃO PAULO, 1997b, p. 948).

Mas Perrenoud (2000a, p. 99) alerta para a criação de ciclos de aprendizagem, "no qual forma entidades globais no interior das quais não ocorre nem reprovação, nem qualquer outra forma de seleção, mostra-se uma condição necessária de progresso". Para o autor, surge a necessidade de "saber como criar ciclos de aprendizagem sem estruturá-lo em etapas anuais reconstruindo insidiosamente graus de programa" (p. 99).

Já Amaral (2008, p. 129) relata que observar a avaliação com os olhos limpos não é tarefa fácil, uma vez que não conseguimos ver com clareza "o funcionamento da sociedade e da própria escola, que são instituições por onde as práticas avaliativas transitam, normalmente, de forma arbitrária e conflituosa". Por sua vez, a avaliação deveria deixar de ser um procedimento decisório quanto à aprovação ou reprovação do aluno. Nesse itinerário, a avaliação: 
[...] é o fato pedagógico pelo qual se verifica continuamente o progresso da aprendizagem e se decide, se necessário, quanto aos meios alternativos de recuperação ou reforço. A reprovação, como vem ocorrendo até hoje no ensino fundamental, constitui um flagrante desrespeito à pessoa humana, à cidadania e a um direito fundamental de uma sociedade democrática. É preciso varrer da nossa realidade a "pedagogia da repetência" e da exclusão e instaurar definitivamente uma pedagogia da promoção humana e da inclusão. O conceito de reprovação deve ser substituído pelo conceito de aprendizagem progressiva e contínua (SÃO PAULO, 1997a, p. 826).

No entanto, Perrenoud (2000b) traz ao debate a questão das decisões de passagem de um ciclo a outro, parecendo assemelhar-se a decisões de aprovação e reprovação, emergindo a pergunta: seria "melhor manter um aluno por mais um ano no mesmo ciclo, correndo-se o risco de retardar seu desenvolvimento e aumentar seu atraso escolar, ou é melhor fazê-lo passar para o ciclo seguinte, ainda que não domine todos os seus pré-requisitos e possa perder seu tempo e agravar as lacunas?" (p. 52).

Longe de responder a esse questionamento, devemos estar atentos, segundo Amaral (2008), à qualidade do ensino oferecido pelas escolas, o qual carece um olhar atento ao ensino por ciclos, sendo que com a reprovação abolida e a avaliação vista como uma função que não mais classifica para excluir, ficamos à mercê de ver os alunos sendo "promovidos" de um ciclo para o outro sem terem acesso adequado ao conhecimento.

Todavia, sob a ótica da Indicação 22/97, "os desafios postos hoje ao ensino fundamental de prover todos os cidadãos com o domínio dos conhecimentos básicos em nossa cultura, a questão é saber como organizar as atividades escolares para que seja superado o fracasso escolar" (SÃO PAULO, 1997b, p. 949).

Não podemos, conforme afirma Amaral (2008), criar a impressão de que a avaliação deixou de existir por não haver reprovação. Além disso, os alunos por sua vez são mantidos dentro da escola, pois esta não mais pode deixá-los de fora; contudo, são fortes candidatos a serem excluídos ao final do ensino fundamental ou médio, apesar de terem um diploma na mão. A autora acrescenta que "foram mantidos na escola mesmo sem aprender, mas serão excluídos pela sociedade por não terem as 'habilidades' deles esperadas” (p. 133).

Dessa maneira, desde a Lei 5.692/71, em relação ao aproveitamento escolar, se reconhece duas situações de alunos: os com aproveitamento suficiente e os de aproveitamento insuficiente. Entretanto, não menciona aluno reprovado, mas de alunos de aproveitamento insuficiente que poderão obter aprovação mediante estudos de recuperação proporcionados obrigatoriamente pelo estabelecimento (BRASIL, 1971).

A LDB 9.394/96, da mesma forma, não traz em seu texto nada sobre a reprovação. A retenção não é mencionada na lei, mas deve "prover meios para a recuperação dos alunos de menor rendimento", além da verificação do rendimento escolar observa-se os seguintes critérios:

a) avaliação contínua e cumulativa do desempenho do aluno, com prevalência dos aspectos qualitativos sobre os quantitativos e dos resultados ao longo do 
período sobre os de eventuais provas finais;

b) possibilidade de aceleração de estudos para alunos com atraso escolar;

c) possibilidade de avanço nos cursos e nas séries mediante verificação do aprendizado;

d) aproveitamento de estudos concluídos com êxito;

e) obrigatoriedade de estudos de recuperação, de preferência paralelos ao período letivo, para os casos de baixo rendimento escolar, a serem disciplinados pelas instituições de ensino em seus regimentos.

Por fim, "a adoção de progressão continuada e a concretização de seus resultados dependem de uma alteração radical na concepção de ensino, de aprendizagem e de avaliação da aprendizagem, rompendo eventuais resistências" (SÃO PAULO, 1997b, p. 950). No entanto, concordamos com Perrenoud (2000a, p. 99), que mesmo "em sua versão mais conservadora, o ciclo de aprendizagem acaba, em princípio, com a reprovação, mas não rompe a estruturação do curso em graus sucessivos e não basta para neutralizar a fabricação das desigualdades".

\section{OS CAMINHOS DA PROGRESSÃO CONTINUADA}

O espaço escolar, como o conhecemos, passa a existir a partir dos séculos XIX e XX. Para Bertagna (2008, p. 75) "é interessante lembrar que a atual forma de organizar o espaço e o tempo escolar - através da seriação - é herança de Comenius (século XVII)". Esse espaço surge para suprir as necessidades, universalizar e "democratizar" a educação realizada no âmbito escolar, pela família e comunidade, uma vez que o processo educacional, apenas, atendia à camada social mais abastada da sociedade. Portanto, esse espaço passa a ser cobrado pelas outras esferas sociais a fim de proporcionar uma educação para todos.

Freitas (2005) afirma que os tempos e espaços da escola são contraditórios e tensos, assim como tensa e contraditória é a sociedade que a cerca. Nesse caso, há uma permanente disputa, a qual reflete as diferentes concepções de educação, as diferentes finalidades educativas atribuídas. Entretanto, a universalização e democratização ocorrem nos países considerados desenvolvidos nos séculos já citados e sendo aplicadas nos países em desenvolvimento ou subdesenvolvidos no século XX e XXI.

Segundo Jacomini (2002), esse tipo de educação estava centrado na transmissão de conhecimento e na seleção dos preparados para seguirem os estudos. Assim, quem não conseguisse alcançar o esperado acabava por ser barrado e, por conseguinte, se evadia.

Como resposta ao caráter excludente da escola, que deveria ser em tese, o espaço de inserção social do indivíduo, passa-se a se pensar em meios que modifiquem a realidade constatada e uma das alternativas seria não mais a avaliação seriada, mas a avaliação por ciclos. Assim, "as tentativas de alterar a organização escolar baseadas em reformas que introduzem a progressão continuada ou os ciclos estão inseridas neste ambiente" (FREITAS, 2005, p. 112).

Barretto e Mitrulis (2001) colocam que análises realizadas sobre a retenção dos estudantes vinham trazendo como consequências um grande prejuízo monetário às instituições públicas e prejuízo de ordem pessoal e social. Esse tema ganha maior repercussão após a Conferência Regional Latino-Americana sobre Educação Primária Gratuita e Obrigatória, 
que a UNESCO organizou em colaboração com a Organização dos Estados Americanos (OEA), realizada em Lima, em 1956. Dessa conferência, tem-se como ponto de concordância a necessidade de acabar com os altos índices de reprovação escolar. Como justificativa para as ações estavam os enormes prejuízos financeiros e perda dos direitos educacionais da maioria das crianças em idade escolar.

Como ações para essa transformação constatada, seria necessária uma revisão do sistema de aprovação na escola primária e um amplo debate com os docentes que ministravam aula a esses estudantes sobre um meio de avaliação que tivesse como primordial a idade do educando e não mais suas avaliações.

Contudo, entre as considerações históricas, no Brasil, em 1890, 85\% da população total brasileira era analfabeta, diminuindo discretamente para 75\% em 1900, segundo Souza, Bueno e Figueiredo (2011). Para a apresentação desses dados, foram considerados:

[...] apenas a população de 15 anos ou mais, $65 \%$ era analfabeta em 1900 . Esse
percentual se mantém até 1920 . Assim sendo, em 1920, '[...] o direito de ler e
escrever era negado a quase 11 milhões e meio de pessoas com mais de 15 anos.
E o que é mais assustador: em 1960, esse mesmo direito era negado a quase 16
milhões' (RIBEIRO, 1994, p. 150, apud SOUZA; BUENO; FIGUEIREDO,
2011, p. 84).

Para Jacomini (2004), existiram quatro grandes momentos nas discussões e experiências de ensino não seriado no Brasil. O primeiro seria datado da década de 1920, com "a defesa do professor Sampaio Dória da adoção de promoção automática no ensino primário paulista, com o objetivo de ampliar o atendimento escolar aos ingressantes, e a proposta de promoção em massa" (p. 404).

O segundo período ocorre na década de 1950, quando alguns dos educadores da época (Dante Moreira Leite e Almeida Júnior):

[...] tendo como referência as experiências de ciclos e progressão continuada inglesas iniciadas em 1944, e a americana, nos estados de Michigan e Kentucky, visitados por Almeida Júnior, defenderam a adoção da promoção continuada, na época chamada de promoção automática, compreendendo-a como uma forma de respeito e responsabilidade diante das diferenças e necessidades individuais na realização de um ensino e de uma aprendizagem para todos (p. 404).

No ano de 1958, o Estado do Rio Grande do Sul criou uma primeira situação de progressão, onde salas de recuperação seriam criadas para ajudar os alunos a recuperarem o conteúdo necessário e assim serem inseridos na sala, que a idade, os colocava (BARRETTO; MITRULIS, 2001).

Lacerda (s/d) coloca que, no Brasil, o regime de progressão continuada, da forma como é conhecida hoje, surgiu "como objeto de discussão já na década de 50, com a denominação de promoção automática, por meio de, pelo menos dois artigos mais conhecidos, um de Almeida Júnior, em 1956 e outro de Dante Moreira Leite, em 1959”. Mainardes 
(2006), sobre o assunto, menciona que nos anos de 1950 há um debate no país acerca do regime, mas sem que este tivesse um alcance prático, e que separou os formuladores. Anísio Teixeira a favor e Luis Pereira, que demonstrava ressalvas sobre o assunto.

Logo em seguida, em 1961, a LDB no. 4.024/61, em seu Artigo 104, prevê a "organização de cursos ou escolas experimentais com currículos, métodos e períodos escolares próprios" (BRASIL, 1961). Entretanto, a mesma Lei coloca em seu Artigo 39: “A apuração do rendimento escolar ficará a cargo dos estabelecimentos de ensino, aos quais caberá expedir certificados de conclusão de séries e ciclos e diplomas de conclusão de cursos". Apesar das escolas experimentais, o processo de avaliação ainda continua a seguir o modelo seriado, conforme o Parágrafo $1^{\circ}$., deste Artigo, o "aproveitamento do aluno preponderarão os resultados alcançados, durante o ano letivo, nas atividades escolares, asseguradas ao professor, nos exames e provas, liberdade de formulação de questões e autoridade de julgamento".

Mas autores como Souza (1998), Neves e Boruchovitch (2004), Bertagna (2010), colocam que a possibilidade da organização não seriada do ensino não se constituiu novidade na legislação que normaliza o ensino institucionalizado. Por conseguinte, essa possibilidade passou a ser explicitada como alternativa na LDB Lei $n^{\circ}$. 5.692/71 (Art. 14) e, atualmente, na LDB n ${ }^{\circ}$. 9.394/96 (Art. 23), onde fica instituída a possibilidade da implantação dos ciclos.

Nesse caminho, nas décadas de 1960 e 1970, os altos índices de repetência e evasão continuam sendo um problema não solucionado. E alguns Estados, como Pernambuco, São Paulo, Santa Catarina e Minas Gerais, fazem algumas modificações que tornam o currículo das escolas primárias mais flexíveis e a adoção do formato do sistema de avanços progressivos (JACOMINI, 2004).

Rossi (2007) destaca que o período da década de 1930 a 1970 estaria submetido pela oferta limitada de vagas e, ao final desse momento, "a democratização do ensino que 'abre as portas da escola' àqueles que antes não tinham esse direito pode significar um primeiro conceito de qualidade" (p. 52).

Souza (1998) com base no Parecer $n^{\circ}$. 360/74 CE $1^{\circ}$. e $2^{\circ}$., Item I - Relatório, do Conselho Federal de Educação, a proposta do sistema de avanços progressivos indica que:

[...] o sistema de avanços implica na adequação dos objetivos educacionais às potencialidades de cada aluno, agrupando por idade e avaliando o aproveitamento do educando em função de suas capacidades. [...] Não existe reprovação. A escolaridade do aluno é vista num sentido de crescimento horizontal; o aproveitamento, numa linha de crescimento vertical. Pelo regime de avanços progressivos, o aproveitamento escolar independe da escolaridade, ou seja, do número de anos que a criança frequenta a escola (SOUSA, 1998, p. 87).

Seguindo a trajetória de Jacomini (2004), o terceiro momento de adoção de ciclos e progressão continuada deu-se, conforme já mencionado, após a Lei n $n^{\circ} .5 .692 / 71$, posteriormente em 1978, e foi implantada no Distrito Federal a proposta de Avanços Progressivos, e 
no Estado do Rio de Janeiro, adotou-se o Bloco Único em 1979. Mais adiante, a década de 1980, para Rossi (2007), foi marcada

[...] pela necessidade de se regularizar a trajetória escolar de milhares de alunos que anualmente eram reprovados e, posteriormente, abandonavam a escola. Para essa regularização foi implantada uma série de medidas, dentre as quais merecem destaque: o regime de progressão continuada, ciclos de escolarização e programas de aceleração da aprendizagem (p. 53).

Nessa década, foi adotado em alguns Estados o Ciclo Básico de Alfabetização (CBA), por exemplo, São Paulo em 1984, Minas Gerais em 1985, Paraná e Goiás em 1988 (JACOMINI, 2004).

A década de 1990 veio consolidar e estabeleceu definitivamente o conceito do regime da progressão de acordo com o previsto na LDB 9.394/96, e, para Jacomini (2004), este seria o quarto momento, constituindo-se das experiências implantadas a partir da nova LDB, tomando como base "as experiências anteriores e a necessidade premente de garantir aprendizagem aos milhares de alunos que têm acesso à escola pública [...]". Olhando de maneira mais detalhada para o Estado de São Paulo, apresenta-se a análise de quatro momentos e experiências distintos:

[...] a Reforma de 1967/68, a implantação do Ciclo Básico de Alfabetização (CBA) em 1983/84, a instituição do regime de progressão continuada nos oito anos do ensino fundamental em 1998, na rede estadual do estado de São Paulo, e a adoção dos ciclos e da progressão continuada na rede municipal de ensino da cidade de São Paulo, em 1992 (JACOMINI, 2004, p. 408).

Houve, entretanto, muitas críticas negativas da sociedade e dos próprios professores sobre essas experiências, fazendo que as mudanças não se efetivassem.

Dados da pesquisa de Neves e Boruchovitch (2004) mostram que, para a maioria dos professores entrevistados $(88,1 \%)$, a implantação dos ciclos e progressão continuada não ajudou a melhorar as condições de ensino e aprendizagem. Os docentes (93,3\%) assinalaram, ainda, que a não reprovação entre as séries está gerando um maior desinteresse dos alunos pelos conteúdos ensinados. E para 91,9\% a promoção automática está permitindo que os alunos progridam de uma série a outra sem se apropriarem dos conteúdos fundamentais (NEVES; BORUCHOVITCH, 2004).

Talvez, para que esse quadro se modifique, devêssemos romper com as resistências dos professores, oferecer condições de tempo e de recursos para que exercitem suas funções. Sob esse olhar as mudanças

[...] na avaliação provocam ansiedade também entre os professores que deverão não só superar uma posição, muito frequente, de individualismo, como também construir coletivamente novas formas de trabalho docente, saindo da avaliação classificatória, que apenas verifica o aproveitamento escolar, para separar os alunos em reprovados e aprovados, ao final do processo, adotando, ao invés 
disso, uma avaliação formativa, capaz de colocar, à disposição do professor e da equipe escolar, informações mais precisas, mais qualitativas, sobre os processos de aprendizagem dos alunos, os quais dependem da estrutura dos conhecimentos a construir e das habilidades a desenvolver em cada área (SÃO PAULO, 1997b, p. 950).

Percebemos que, na década de 1990, há várias transformações sociais que reiteram a necessidade de novas formas de aprendizagem. É amplamente divulgada a concepção de que o indivíduo aprende em todos os momentos de sua vida e assim já não mais era imprescindível o aprendizado em cada série das matérias propostas.

Já nos anos subsequentes, principalmente com a LDB 9.394/96 e os Parâmetros Curriculares Nacionais, há a reiteração da organização curricular por ciclos. Assim, o Estado de São Paulo, em 1997, instituiu o regime de Progressão Continuada por meio do CEE. O regime seria implementado no ensino fundamental de oito anos (atualmente nove anos) com a participação dos Conselhos Tutelares, cuja principal função é a de garantir a frequência dos estudantes à escola.

A partir de 1998, a Secretaria de Educação de São Paulo passa a funcionar em ciclos sob o regime de Progressão Continuada, dividindo-se em dois ciclos: de $1^{\mathrm{a}}$ a $4^{\mathrm{a}}$ série (primeiro ao quinto ano) e da $5^{\mathrm{a}}$ a $8^{\mathrm{a}}$ série (sexto ao nono ano). Essa mudança traria benefícios tanto do ponto de vista pedagógico como econômico. Assim, o sistema escolar deixaria de contribuir para o rebaixamento da autoestima de elevado contingente de alunos reprovados (SÃO PAULO, 1997c).

Nesse sentido, “a progressão continuada como medida político-pedagógica não tem a função de garantir, impedir ou dificultar a aprendizagem dos alunos, mas o objetivo de romper com o processo de seleção e exclusão operado pela reprovação" (JACOMINI, 2009, p. 508). Contudo, o regime de progressão continuada deveria atentar para a sua construção histórica, rompendo com alguns paradigmas, para que não se torne um fator de exclusão dos alunos ao final de cada ciclo ou ainda, como já mencionado ao longo deste texto, formar pessoas sem as mínimas competências para atuar no mercado e/ou para entrar em uma universidade. Todavia, a busca pela compreensão e o desenvolvimento desse regime no interior das escolas se fazem necessários, além do entendimento dos professores, alunos e pais.

Conforme pesquisa realizada, em 2011, pelo Instituto Nacional de Estudos e Pesquisas Educacionais Anísio Teixeira (Inep), o número de matrículas dos estudantes na educação básica vem se adequando desde 2007, o que, segundo o relatório, se deve em grande parte às políticas adotadas pelos órgãos oficiais para reduzir as taxas de evasão e reprovação dos estudantes. Mas de acordo com os dados aferidos a partir das provas oficiais (Prova Brasil e teste de Pisa), percebe-se que a qualidade do ensino oferecido no país ainda não corresponde às necessidades para a capacitação dos indivíduos e sua inserção social.

Sob a égide de melhorar as taxas de aprovação e permanência dos alunos na escola, a Progressão Continuada seria, também, capaz de fazer que os estudantes recuperassem a autoestima, além de diminuir os gastos com a educação. Segundo dados do site "Todos pela 
Educação", de cada 100 escolas no país, 25 aderiram ao regime de progressão e o Estado de São Paulo é a maior rede de ensino do país, em que em cada 100 escolas, 99 aderiram à progressão continuada por meio de ciclos. Nesse regime, os alunos são avaliados por ciclos e não por série e assim o aluno não reprova se não alcançar o que é determinado para cada série, pois cada um tem um tempo próprio para aprender e assim necessita apenas de auxílio em recuperação contínua e paralela para alcançar os colegas da mesma idade.

Esse regime é avaliado pela secretaria por meio do Sistema de Avaliação do Rendimento Escolar do Estado de São Paulo (SARESP) desde 1996, e tem como objetivo fornecer à Secretaria dados que auxiliem na tomada de decisões e medidas que visem a contribuir com a melhoria da educação no Estado de São Paulo. Faz-se isso por meio do rendimento escolar e fatores que colaboram para os dados exibidos. A avaliação ainda apresenta à escola o seu rendimento individual, mostrando as melhoras e dificuldades. Estas últimas carecem de um melhor planejamento e de políticas internas, próprias da escola, que possam contribuir para o avanço e melhoria da qualidade do ensino e aprendizagem.

O SARESP leva em consideração não apenas os resultados cognitivos dos alunos, mas também o índice de aprovação dos estudantes a cada série/ano, que resultam no índice de avaliação da escola e no alcance ou não das metas estabelecidas pela secretaria para cada unidade escolar. As primeiras avaliações foram aplicadas a todos os estudantes de todas as séries. Entretanto, atualmente, avaliam o $5^{\circ} ., 7^{\circ}$., $9^{\circ}$. ano do ensino fundamental e $3^{\circ}$. ano do ensino médio.

Segundo Rossi (2007), surge, além do SARESP, um significado para a qualidade como expressão da aprendizagem dos estudantes, aferida mediante testes padronizados em larga escala, por exemplo, SAEB (Sistema de Avaliação da Educação Básica), o ENEM (Exame Nacional do Ensino Médio), e o SINAES (Sistema Nacional de Avaliação do Ensino Superior), este aplicado ao Ensino Superior.

Mesmo com o acompanhamento da qualidade, há três problemas centrais que perpassam a implantação das políticas educacionais brasileira e formam o cenário no qual são construídas as concepções, opiniões e ações dos educadores, como descreve Jacomini (2004, p. 406):

[...] 1) geralmente as propostas são elaboradas sem que se tenha uma avaliação sobre os resultados das políticas que as antecederam; 2) raramente elas são discutidas com os educadores e os usuários da escola pública; 3) e, normalmente, não são oferecidas as condições materiais e organizacionais para que elas sejam implementadas a contento.

Por fim, a CEE destaca na Indicação $n^{\circ}$. 8/97, que o "regime de progressão continuada em ciclo único no ensino fundamental pode vir a representar a inovação mais relevante e positiva na história recente da educação no Estado de São Paulo". Contudo, esse processo deve ser amplamente debatido nas diferentes esferas da sociedade, a fim de que se garanta, efetivamente, a democracia e a participação dos agentes sociais envolvidos na educação e não apenas decisões de gabinete. 


\title{
O REGIME DE PROGRESSÃo CONTINUADA: ENTRE BENEFÍCIOS E AVANÇOS (OU NÃo)
}

De acordo com Neves e Boruchovitch (2001), em suas pesquisas com estudantes do Ensino Fundamental, ao observar o impacto do regime de Progressão Continuada na motivação dos alunos para aprender com o sistema que não se pauta pelas notas, mostraram, em 2001, que a implementação de ciclos e da progressão continuada não foram suficientes para melhorar a aprendizagem, as condições de aprendizagem em que estão inseridos os estudantes. Segundo as autoras, para que os objetivos propostos para a implementação da Progressão Continuada fossem alcançados, seria necessário investir em estratégias que possibilitem uma reestruturação de toda a organização escolar, como o "tempo, espaço, avaliação, currículo, trabalho coletivo, relação professor-aluno e escola comunidade, formação contínua dos professores e gestão escolar" (NEVES; BORUCHOVITCH 2011, p. 83).

Freitas (2002) pontua a importância dos ciclos como forma de resistência à lógica da seriação, já que ciclos devem ser defendidos por permitir a resistência e hierarquização e exclusão social vigentes, que tornam a reproduzir o panorama social de deixar os que não têm acesso à cultura hierarquizada à margem das benesses da sociedade.

Assim, a escola deveria ser o local da incorporação social, capaz de ajudar os indivíduos a se formarem e atuarem socialmente, mas eles são alijados sob a desculpa de que não tiveram competência para se formarem. Sobre o assunto, Souza (1998, p. 85) coloca que a questão é

\begin{abstract}
[...] a constituição da escola que se paute pelo compromisso com a inclusão escolar e social de todos rompendo-se com a noção, tradicionalmente, assimilada de que sua finalidade é transmitir um dado conjunto de informações que devem ser assimiladas por todos os alunos, mas que, 'já se sabe', nem todos têm condições de dominá-las, nos tempos e nas condições pré-estabelecidas, convivendo-se, assim, com os altos e persistentes índices de fracasso escolar.
\end{abstract}

Dessa maneira, concordamos com Jacomini (2011), ao dizer que a organização do ensino em ciclos pressupõe mudanças na compreensão do desenvolvimento e da aprendizagem como no tempo e espaço escolar, no conteúdo, na metodologia, na avaliação e nas relações entre os envolvidos no processo educativo.

Viégas (2002) acompanhou um grupo de professores da rede estadual paulista por um semestre para saber o que os professores pensavam e como lidavam com a Progressão Continuada, por meio da análise da aprovação, reprovação, avaliação, reforço, frequência e trabalho coletivo. Para a autora, o aspecto econômico sobressaía-se e isso era acompanhado da total falta de condições objetivas para o sucesso, sendo que essas condições foram lembradas na implementação, mas esquecidas logo depois. Além disso, lembra que embora seja pregada a continuidade, é a descontinuidade, imposta pela migração de professores, supervisores, alunos, diretores, que a marca. Deixa claro que a Progressão Continuada foi implantada com o intuito de diminuir a reprovação, mas tendo como justificativa primeira 
o fato de que os alunos tinham o direito à educação, o que não ocorria ao serem excluídos por meio da reprovação.

Outro ponto que chama atenção é o fato de o regime ter sido imposto sem a devida discussão. Em suas palavras:

\begin{abstract}
Como consequência, pois, não se tem a transformação da realidade excludente da escola, mas sim o surgimento ou potencialização de outros sintomas seus, que, no entanto, não mais se refletem nos índices educacionais: a defasagem de conhecimento, o aumento da indisciplina ou da apatia discente, a ilusão da inserção, o analfabeto escolarizado (VIÉGAS, 2006, p. 167).
\end{abstract}

Isso faz que fatores que corroboram para a produção da má qualidade do ensino sejam negligenciados, fazendo muitos alunos deixarem de fato de ser reprovados, mas passarem a ser aprovados por decreto, ou seja, há a promoção automática.

A avaliação não poderia ser utilizada como "instrumento de meritocracia, premiando aqueles cujo desempenho está de acordo com os padrões de normalidade instituídos pela escola - a qual, por sua vez, é instituída pela sociedade - e punindo os que não alcançam os resultados esperados" (AMARAL, 2008, p. 129). Nesse caso, o processo de avaliação está mais preocupado com "o desempenho quantitativo dos alunos do que com a aprendizagem que se desenvolve efetivamente nas escolas, a avaliação assim concebida e desenvolvida deixa transparecer um enfoque totalmente voltado para o produto da educação" (p. 129).

Ribeiro (1991), ao debater sobre as políticas públicas e as implicações destas no espaço escolar, pontua que os professores estaduais do Estado de São Paulo têm passado por várias mudanças, principalmente, a partir do governo de Mário Covas, em 1998, com a implantação do sistema de Progressão Continuada. O autor coloca que os professores não participaram ativamente da construção dessa nova política, o que gerou angústias e a ideia, por parte dos docentes, de que o único objetivo do regime de Progressão Continuada era diminuir as evasões e reprovações, diminuindo os gastos. Uma das características do Estado Mínimo sob a ótica neoliberal.

Assim, pondera-se que as políticas públicas relacionadas à educação em curso são incapazes de gerar mudanças e melhorias na formação e, por conseguinte, na vida dos estudantes na educação nacional ou estadual.

Jacomini (2004) afirma que um dos principais problemas da implantação das políticas públicas de modo geral é a aplicação de uma nova proposta sem analisar os resultados do que já foi feito, raramente há discussão com os agentes mais impactados educadores e os que da escola pública usufruem e a falta de infraestrutura quanto a materiais e organização. Quando analisa a Progressão Continuada na rede estadual de ensino, chama a atenção para o fato de ter sido imposta contra a vontade de professores, sindicatos e pelos usuários/participantes da educação pública estadual.

A resistência foi que os docentes se depararam com salas de aulas ainda mais lotadas do que no regime seriado anterior, professores não efetivos foram despedidos às centenas, as Horas de Trabalho Pedagógico Coletivo (HTPCs) não aumentaram e assim era insufi- 
ciente para a preparação e discussão sobre o novo regime e as modificações necessárias quanto ao trabalho pedagógico para que logre sucesso (JACOMINI, 2004).

Contudo, observa-se que a avaliação autoriza o poder da escola e do professor e a associação destas esferas "joga muitas das propostas "inovadoras" da avaliação em um terreno dicotômico: formas autoritárias versus formas democráticas de avaliar" (FREITAS, 2010, p. 95).

Já Vasconcelos (2008) procura analisar a redução dos ciclos ocorrida no ano de 2007 no regime de Progressão Continuada no Estado de São Paulo, chamando a atenção do leitor para o fato de que o objetivo primeiro da implantação do regime era a correção da distorção dos alunos quanto à idade/série - foram alcançados. Cabe, no entanto,

\footnotetext{
[...] ressalvar que atividades de reforço e recuperação paralela, além de horas de trabalho pedagógico coletivo, sempre foram recomendadas a todas as escolas como ações continuadas imprescindíveis. Entretanto, na prática, sua oferta, com o passar do tempo, apresentou-se de forma bastante irregular, isto é, deixada a critério de cada equipe escolar, nem sempre ocorreu com a regularidade desejável, comprometendo, portanto, os resultados esperados com a adoção da progressão continuada (VASCONCELOS, 2008, p. 80).
}

Como pontos positivos, a autora coloca o baixo índice de evasão no ensino fundamental e a ausência do aluno multirrepetente, que perdia a autoestima e se evadia do ambiente escolar. Por fim, expõe que a redução dos ciclos ajuda a sanar os problemas que o regime de ciclo apresentava, resguardando os pontos positivos.

Spada (2007) faz uma revisão do caráter excludente da escola tradicional, que se torna ineficiente com a mudança social trazida pela urbanização e do desenvolvimento industrial que trouxe a necessidade de garantir educação à população, em geral, e não mais apenas aos filhos da elite. Retoma, assim, as concepções em que se firmaram os ideais da Progressão Continuada, que via o saber como progressivo e assim nada poderia ser negligenciado.

Ao analisar, por fim, uma realidade concreta da implantação da Progressão Continuada, deve-se atentar para um fator até aqui ainda não colocado: o aumento da retenção em finais de ciclo. Quando há a possibilidade dessa e que só será possível alcançar avanços quanto à aprendizagem quando houver investimento em infraestrutura, na formação de professores que saibam como ajudar os discentes de acordo com seu ritmo pessoal (SPADA, 2007).

Freitas (2002) destaca com pessimismo o debate sobre as políticas neoliberais na educação. Entre essas políticas, analisa a Progressão Continuada por meio de relatos de professores em um curso de especialização em Campinas. Segundo o autor, o regime deve ser analisado pensando que o Estado percebeu que a evasão e a reprovação trazem custos combinados com a exclusão dos alunos por meio da progressão pouco estruturada, que não consegue ajudar o aluno e apenas o passa de uma série para outra.

$\mathrm{O}$ autor coloca também que se a avaliação formal deixa de ser aplicada no regime de progressão continuada, a avaliação informal ocorre, e volta a reforçar o que outros autores já disseram: os professores não foram preparados para a nova forma de ensino. 
Além disso, o regime de progressão continuada do Estado de São Paulo, apesar de passados anos de sua implementação, necessita de algumas mudanças. Nesse sentido, Bertagna (2008, p. 80) aponta algumas delas, como:

[...] na atuação pedagógica para repensar os modelos de atuação docente. Propõem-se, para isso, estratégias de ensino distintas, dirigidas ao conjunto da classe (conhecimentos comuns), e atividades para pequenos grupos, possibilitando a troca de experiências (os mais experientes monitoram os inexperientes) enfatizando-se, assim, um ensino com base na heterogeneidade dos alunos.

Enfim, os estudos acadêmicos que acompanharam a implantação da proposta da progressão continuada no Estado de São Paulo indicam que não houve rompimento com a forma de organizar os tempos e espaços escolares e sim uma acomodação da forma seriada, agrupando-se séries com a denominação de ciclos, pouco incentivando a discussão da forma escolar e sua finalidade (BERTAGNA, 2008). Ao percorrer esse trajeto da progressão continuada, verificamos a necessidade de mais investigações empíricas que apresentem informações para uma análise criteriosa sobre esse regime. Algumas lacunas precisam ser preenchidas para que possamos melhorar o processo de ensino e aprendizagem, ao invés de achar um culpado para o nosso fracasso educacional, seja nos Estados ou no País.

\section{CONSIDERAÇões FINAIS}

A Progressão Continuada foi implantada no Estado de São Paulo, tendo como base a LDB 9.394/96, que dispunha sobre a possibilidade de organizar o ensino em ciclos e se deu efetivamente com Deliberação Conselho Estadual de Educação (CEE) nº. 9/97 e homologada pela Resolução da Secretaria de Educação (SE) de 4/8/97. O Estado de São Paulo, após vários debates, implantou o regime na rede estadual a partir de 1998.

Entre os caminhos percorridos neste trabalho, ao analisar o regime de progressão continuada do Estado de São Paulo, verificamos que o principal objetivo seria acabar com a reprovação e, por conseguinte, otimizar o uso de recursos, a alegação de que esse regime melhoraria a autoestima do aluno. No Estado de São Paulo, foi possível perceber que a Progressão Continuada foi pensada durante vários anos, não apenas na esfera estadual, mas na esfera nacional, sempre tendo como foco a diminuição da evasão escolar.

Esse regime, no Brasil, como o conhecemos hoje, foi objeto de discussão desde a década de 1950, perpassando indireta e diretamente nos seguintes documentos oficiais: LDB 4.024/61 de 1961; Lei Estadual no. 10.403, de 6 de julho de 1971; LDB 9.394/96; na Indicação no. 08/97; e na Deliberação CEE nº. 9/97.

Na década de 1990, houve a consolidação do regime de progressão continuada, que se estabeleceu definitivamente no Estado de São Paulo. Tal mudança deveria trazer benefícios tanto do ponto de vista pedagógico como econômico. Entretanto, constatamos que os docentes, de certa forma, acabam apontando o regime como o grande culpado pelas dificuldades em sala de aula como indisciplina, desinteresse e aprovação sem qualquer 
conhecimento, acarretando muitas vezes a exclusão social, ou seja, não conseguindo a sua inserção social conforme descrita no decorrer do texto.

Os alunos, por sua vez, mostram-se, muitas vezes, desinteressados, pois não têm consciência da importância da educação e por terem a sensação de não serem reprovados, não veem sentido em entregar trabalhos, fazerem provas, se esforçarem. Pensam a curto e médio prazo, esquecendo-se das exigências sociais futuras. Portanto, para Contiero e Tommasiello (20150, p. 121), a postura da escola, dos docentes, das famílias dos alunos e da sociedade em geral a respeito do Regime de Progressão Continuada seria controversa, "no sentido de que os problemas de aprendizagem e fracasso escolar têm sido atribuídos ao RPC (Regime de Progressão Continuada), pois há um sentimento geral de que a escola rebaixou seus padrões de qualidade, pois não reprova mais ninguém”.

Dessa forma, percebeu-se, após a análise dos autores, que há mais pontos negativos do que positivos na implementação do regime. Entre eles, destacamos os professores, os quais praticamente foram forçados a realizarem as mudanças impostas pelo regime sem estarem totalmente conscientes das ações e implicações desse para o trabalho que ocorreria na sala de aula. Nesse caso, acreditamos que, pela não participação efetiva dos professores na construção desse regime, da falta de conhecimento dos órgãos públicos referente à realidade das escolas e dos alunos, entre outros, a progressão continuada ainda seja um tabu no contexto educacional público do Estado de São Paulo.

Outro ponto bastante problemático seria a avaliação do regime da Progressão Continuada estar atrelada ao índice de aprovação/reprovação e evasão, o que faz que muitos estudantes sejam aprovados sem terem conseguido desenvolver as habilidades mínimas necessárias, sendo promovidos de forma automática. E essa sensação de não reprovação gerada no interior das escolas pode contribuir para a formação de alunos com dificuldades de aprendizagem, ou seja, alunos formados (certificados com diploma) sem saber, por exemplo, interpretar textos e resolver problemas.

A falta de conhecimento, interpretação e distorção da Progressão Continuada de acordo com os diferentes interesses pode comprometer o futuro de muitos alunos e, talvez, frustrando-os ainda mais quando estiverem certificados frente aos desafios da sociedade, no mercado de trabalho, ingresso no ensino superior etc. Portanto, não se pode esperar que somente ao final do Ensino Fundamental I os alunos sejam retidos (no quinto ano) ou no Ensino Fundamental II (nono ano) seriam retidos por habilidades e competências não desenvolvidas para série/ano em que se encontram.

A partir desses apontamentos, seria pertinente refletirmos e desenvolvermos investigações empíricas referente aos reais e ocultos objetivos do regime de Progressão Continuada? Quais ações a serem desenvolvidas de formação, seja inicial ou continuada, de professores e equipe gestora da escola que os capacitassem para trabalhar com esse regime? Como deveria ocorrer o planejamento de ensino e aprendizagem e as diferentes formas de avaliação dos alunos no contexto da Progressão Continuada? Quais distorções que realmente ocorreram no desenrolar dos últimos anos a fim de garantir apenas índices estatísticos para apresentar aos diferentes órgãos/instituições nacionais e internacionais, com único intuito 
de angariar recursos financeiros? Como propiciar ao aluno e professor um ambiente favorável à educação de qualidade? Quais ações, no âmbito das políticas públicas, necessárias para avançar no discurso e, principalmente, no dia a dia da escola a fim de garantir o direito de uma educação de qualidade?

Esses e outros questionamentos se fazem necessários para avançarmos na melhoria da educação como um todo e na emancipação dos alunos na chamada sociedade do conhecimento. Não se pode pensar mais em uma educação que forma pessoas sem conhecimento, senso crítico, de maneira superficial, mediante os desafios impostos pelo sistema econômico e social vigente no país e cada vez mais envolto pelas tecnologias. Portanto, devemos levar em consideração se seremos capazes de tomar a direção mais coerente e próxima da realidade, corroborando na realização de um trabalho docente consciente de sua responsabilidade no processo de ensino e aprendizagem.

\section{REFERÊNCIAS}

AMARAL, M. C. E. Avaliação nos ciclos: adiamento da exclusão? Práxis Educativa, Ponta Grossa, v. 3, n. 2, p. 129-133, jul./dez. 2008. Doi: <http://dx.doi.org/10.5212/ PraxEduc.v.3i.2.129133>. Acesso em: 12 de maio de 2012.

ANDRÉ, M. E. D. A. Etnografia da prática escolar. Campinas: Papirus, 1995.

BARRETTO, E. S. S.; MITRULIS, E. Trajetória e desafios de ciclos escolares no País. Estudos Avançados, vol. 15 nº. 42 mai./ago. São Paulo, 2001.

BERTAGNA, R. H. Avaliação e progressão continuada: o que a realidade desvela. Pro-Posições, v. 21, n. 3 (63), set./dez. Campinas, 2010.

. Ciclos, Progressão Continuada e Aprovação Automática: contribuições para a discussão. Educação: Teoria e Prática - v. 18, n. 31, jul./dez. Rio Claro, 2008.

BRASIL. Lei $\mathbf{n}^{\mathbf{0}}$. 11.274, de 6 de fevereiro de 2006. Altera a redação dos arts. 29, 30, 32 e 87 da Lei no 9.394, de 20 de dezembro de 1996, que estabelece as diretrizes e bases da educação nacional, dispondo sobre a duração de 9 (nove) anos para o ensino fundamental, com matrícula obrigatória a partir dos 6 (seis) anos de idade.

. Lei $\mathbf{n}^{0}$. 5.692, de 11 de agosto de 1971. Fixa Diretrizes e Bases para o ensino de $1^{\circ}$. e $2^{\circ}$. graus, e dá outras providências. Revogada pela Lei $\mathrm{n}^{\circ}$. 9.394, de 20.12.1996. Nacional.

. Lei nº. 4.024, de 20 de dezembro de 1961. Fixa as Diretrizes e Bases da Educação

. Parâmetros Curriculares: introdução aos parâmetros curriculares nacionais / Secretaria de Educação Fundamental. Brasília: MEC/SEF, 1997.

CAVALCANTI NETO, A. L. G.; AQUINO, J. L. F. A avaliação da aprendizagem como um ato amoroso: o que o professor pratica? Educação em Revista, ago. 2009, vol. 25, n. 2, p. 223-240. 
CONTIERO, A. S.; TOMMASIELLO, M. G. C. O regime de progressão continuada no Estado de São Paulo: indicadores e perspectivas para novas pesquisas. Comunicações, Piracicaba, ano 22, n. 1, p. 119-140, jan./jun. 2015. DOI: <http://dx.doi.org/10.15600/2238$-121 \mathrm{X} / \mathrm{comunicacoes.v22n1 \textrm {p } 1 1 9 - 1 4 0 >}$

CORREA, C. B., PIOTTO, D. C. Progressão Continuada ou seriação? Um passo para frente dois para trás... Cadernos Anpae, nº. 8. Vitória Espírito Santo: UFES, 2009.

FALSARELLA, A. M. Repercussões das Políticas Educacionais no Âmbito Escolar. Meta: Avaliação. Rio de Janeiro, v. 5, n. 15, p. 254-271, set./dez. 2013.

FREITAS, L. C. A internalização da exclusão. Educação e Sociedade, v. 23, n. 80, set. Campinas, 2002. Disponível em: <http://www.scielo.br/scielo.php?pid=S0101$-73302002008000015 \&$ script=sci_arttext $>$. Acesso em: 15 de maio de 2012.

. Avaliação: para além da “forma escola”. Educação: Teoria e Prática, v. 20, n. 35, jul./dez. Rio Claro, 2010.

. Eliminação Adiada: novas formas de exclusão introduzidas pelas reformas. Pro-Posições, v. 16, n. 3 (48), set./dez. Campinas, 2005.

JACOMINI, M. A. Educar sem reprovar: desafios de uma escola para todos. Educação e Pesquisa, v. 35, n. 3, set./dez. São Paulo, 2009.

LACERDA, S. S. C. No sistema de avaliação educacional do Estado de São Paulo uma pimenta chamada "Progressão Continuada", das leis ao cotidiano escolar. Progressão Continuada: afinal, de onde vem esta história? FAFIBE: s/d Disponível em: $<$ http://www.unifafibe.com.br/revistasonline/arquivos/revistafafibeonline/sumario/9/18052011155317.pdf $>$. Acesso em: 15 de junho de 2015.

LÜDKE, M.; ANDRÉ, M. E. D. A. Pesquisa em educação: abordagens qualitativas. São Paulo: EPU, 1986.

MAINARDES, J. Organização da escolaridade em ciclos no Brasil: revisão de literatura e perspectivas para a pesquisa. Educação e Pesquisa, v. 32, n. 1, p. 11-30, jan./abr. São Paulo, 2006.

NEVES, E. R. C.; BORUCHOVITCH, E. A Motivação de Alunos no Contexto da Progressão Continuada. Psicologia: Teoria e Pesquisa, jan./abr. vol. 20 n. 1. Brasília, 2004.

PERRENOUD, P. Pedagogia diferenciada: das intenções à ação. Porto Alegre: Artes Médicas Sul, 2000a.

Dez novas competências para ensinar. Porto Alegre: Artes Médicas Sul, 2000b.

RIBEIRO, S. C. A pedagogia da repetência. Revista Tecnologia Educacional, v. 19, n. 97, nov./dez. Rio de Janeiro, 1990.

ROSSI, L. O Discurso Oficial da Qualidade em Educação: análise dos documentos legais da Secretaria de Estado de Educação de São Paulo. Educação: Teoria e Prática, v. 17, n. 29, jul./dez. Rio Claro, 2007. 
SÃO PAUlO (Estado). Deliberação CEE Nº. 9/97. São Paulo, 1997a. Disponível em: $<$ http://www.crmariocovas.sp.gov.br/pdf/diretrizes_p0820-0830_c.pdf $>$. Acesso em: $14 \mathrm{de}$ maio de 2012.

. Deliberação CEE No 22/97. São Paulo, 1997b. Disponível em: <http://www.crmariocovas.sp.gov.br/pdf/diretrizes_p0947-0952_c.pdf $>$. Acesso em 14 de maio de 2012.

. Secretaria da Educação. Legislação de Ensino Fundamental e Médio. Estadual. Unificação de Dispositivos Legais e Normativos relativos ao Ensino Fundamental e Médio. São Paulo, Secretaria da Educação, 2008. Disponível em: $<\underline{\text { http://lise.edunet. }}$ sp.gov.br/legislacaocenp/Unificacao_27_04_10.pdf $>$. Acesso em: 10 de maio de 2012.

SOUZA, S. M. Z. L. O significado da avaliação da aprendizagem na organização do ensino em ciclos. Pro-Prosições, vol. 9, n. 3 (27), nov. Campinas, 1998.

SOUZA; A. C. de.; BUENO, C. A. R.; FIGUEIREDO, I. M. Z. Alternativas para melhorar o fluxo escolar no ensino fundamental: promoção automática e correção da defasagem idade-série. Cadernos de Educação: FaE/PPGE/UFPel, [39]: 83-106, mai./ago. Pelotas, 2011.

SPADA, F. C. Um estudo sobre a progressão continuada. Revista Científica Eletrônica de Pedagogia, ano V - n. 10, jul. Periódicos Semestral. Garça, 2007. Disponível em: $<\underline{\text { http:// }}$ www.revista.inf.br/pedagogia10/pages/artigos/edic10-anov-art06.pdf $>$. Acesso em: $12 \mathrm{de}$ maio de 2012.

VASCONCELOS, M. L. M. C. Progressão Continuada: porque a revisão de ciclos? Revista Lusófona de Educação, $\mathrm{n}^{\circ}$. 11, Lisboa, 2008. Disponível em: <http://www.scielo.oces. mctes.pt/scielo.php?pid=S164572502008000100005\&script=sci_arttext $>$. Acesso em: 22 de abril de 2012.

VIÉGAS, L. S. Progressão Continuada e suas repercussões na escola pública paulista: concepções de educadores, 2002, 250 p. Dissertação (Mestrado). Instituto de Psicologia, Universidade de São Paulo, 2002.

\section{DADOS DOS AUTORES:}

\section{Karen Fabiane Leonel Corrêa}

Mestre em Letras - Profletras - Unesp Assis; Graduação em Letras pela Universidade Estadual Paulista Júlio de Mesquita Filho(2002); Graduação em Pedagogia pela Universidade Federal de São Carlos(2012), especialização em Língua Estrangeira Moderna pela Universidade Estadual Paulista Júlio de Mesquita Filho(2011) e especialização em Fundamentos Críticos da Literartura pela Universidade Estadual Paulista Júlio de Mesquita Filho(2005). Atualmente é PEBII - Português da Secretaria da Educação do Estado de São Paulo e PEBII - Inglês da Secretaria da Educação do Estado de São Paulo. 


\section{Evandro Antonio Corrêa}

Doutor em Ciências da Motricidade -Pedagogia da Motricidade Humana UNESP; Mestre em Ciências da Motricidade -Pedagogia da Motricidade Humana UNESP/Rio Claro; Especialista em Metodologia e Gestão para Educação a Distância - Universidade Anhanguera Uniderp; Especialista em Lazer e Animação Sócio-Cultural - UEL/PR; Especialista em Educação Ambiental - SENAC/RJ; Licenciatura Plena em Educação Física pela Escola Superior de Educação Física de Avaré (1998); Membro do NEPEF - Núcleo de Estudos e Pesquisa em Formação Profissional no Campo da Educação Física UNESP-Rio Claro; Professor na Faculdades Integradas de Jau; Professor Faculdade Gran Tietê Barra Bonita; Membro pesquisador Associação Brasileira de Pesquisa e Pós Graduação em Estudos do Lazer (ANPEL); Membro Grupo de estudos socioculturais, históricos e pedagógicos da Educação Física Unesp-Bauru; Membro Núcleo de Estudos e Pesquisa das Abordagens Táticas nos Esportes Coletivos (NEPATEC) Unesp-Bauru. Tem experiência na área de Educação Física com ênfase em formação e intervenção profissional, atuando principalmente nos seguintes temas: Formação, Intervenção, Educação Física Escolar e tecnologia, Lazer e atividades de aventura.

Submetido em: 21/09/2016

Aceito em: 18/02/2018 